\section{Filling Effectiveness and Dentinal Penetration of Endodontic Sealers: A Stereo and Confocal Laser Scanning Microscopy Study}

Rogério Vieira Silva ${ }^{1}$, Frank Ferreira Silveira', Martinho Campolina Rebello Horta ${ }^{1}$, Marco Antônio Húngaro Duarte ${ }^{2}$, Bruno Cavalini Cavenago ${ }^{2}$, Ivaldo Gomes de Morais², Eduardo Nunes ${ }^{1}$

\author{
'Department of Dentistry, \\ PUCMG - Pontifícia Universidade \\ Católica de Minas Gerais, Belo \\ Horizonte, MG, Brazil \\ ${ }^{2}$ Bauru Dental School, \\ USP - Universidade de São \\ Paulo, Bauru, SP, Brazil
}

Correspondence: Dr. Frank Ferreira Silveira, Praça Dr. Augusto Gonçalves 146/909, 35 680-054 ltaúna, MG, Brasil. Tel: + 55-37-3241-0996. e-mail: frankfoui@uol.com.br

\begin{abstract}
The aim of this study was to evaluate the filling effectiveness and dentinal penetration of the sealers AH Plus, Pulp Canal Sealer EWT, Sealapex and MTA Fillapex applied according to the vertical condensation technique using thermoplastic gutta-percha. Forty singlerooted teeth were selected. After chemical-mechanical preparation and root-canal filling, sections of the root $(2,4$ and $6 \mathrm{~mm}$ from the apex) were obtained and analyzed by stereo microscopy and confocal laser scanning microscopy. Data were tabulated and statistically analyzed. With regard to the assessment of void spaces in the filling material at $2 \mathrm{~mm}$ from the apex, the sealers showed similar results, but at 4 and $6 \mathrm{~mm}$ from the apex, MTA Fillapex had inferior performance compared to AH Plus (at $4 \mathrm{~mm}$ ), Pulp Canal Sealer EWT (at 4 and $6 \mathrm{~mm}$ ) and Sealapex (at $6 \mathrm{~mm})(p<0.05)$. With regard to the penetration into dentinal tubules at $2 \mathrm{~mm}$ from the apex, the sealers also showed similar results, but at 4 and $6 \mathrm{~mm}$ Pulp Canal Sealer EWT had an inferior performance compared to MTA Fillapex and AH Plus, respectively $(p<0.05)$. All four sealers were found to be similar regarding adaptation of the filling material to the root canal walls, except the MTA Fillapex, which showed failures at 4 and $6 \mathrm{~mm}$ from the root apex. With regard to the ability to penetrate into the dentinal tubules, the sealers were found to be equivalent, except for the Pulp Canal Sealer EWT as it had poorer results at 4 and $6 \mathrm{~mm}$ compared to MTA Fillapex and AH Plus, respectively.
\end{abstract}

Key Words: confocal laser microscopy, dental sealers, root canal filling.

\section{Introduction}

The most frequent cause of apical periodontitis is the bacterial infiltration resulting from caries and/or crownroot fractures, which can reach the system of root canals and dentinal tubules. Microorganisms with their by-products account for the start and/or maintenance of the periapical inflammatory process (1).

Chemical-mechanical preparation of root canals has fundamental importance for a successful clinical therapy, since it allows disinfection of the endodontic space by the action of chemical substances (e.g. sodium hypochlorite), which not only are bactericidal agents but also remove debris and organic remnants, thus reducing the levels of microorganisms and favoring the process of periapical tissue repair (2).

Complete sealing of the root canal system (RCS) is a challenge to be achieved during the endodontic therapy, since the quality of the root canal filling is directly related to the chemical-mechanical preparation, whose objective is to act on anatomical irregularities, curves, isthmuses, and ramifications. Filling these complex anatomies is as difficult as cleaning them because the aim is the three-dimensional sealing of the entire endodontic cavity (3).

Endodontic sealers play an important role as they aid sealing the endodontic cavity by filling re-entrances, irregular spaces and dentinal tubules, all areas inaccessible for endodontic instruments, thus improving the adaptation of root filling at the dentin-material interface $(4,5)$. Penetration of endodontic sealers also presents advantages because they are biologically beneficial, due to their antibacterial effects on the infected dentinal tubules (6).

The flow of endodontic sealers is related to their physical-chemical properties as well as to a good root canal sealing at the moment of root filling (7). Some properties of root canal sealers are well known. Zinc oxide-eugenol sealers have antibacterial activity, while presenting some toxicity when placed directly on vital tissues (8); resin-based sealers have an efficient bond strength to root dentin (9); calcium hydroxide-based sealers present biocompatibility, low cytotoxicity, and antimicrobial properties (10); and recently MTA-based sealers present excellent physicochemical properties (11). However, there is no information regarding the effectiveness of root canal filling and dentinal penetration of MTA-based sealers. The aim of this ex-vivo study was to evaluate the root canal filling and dentinal penetration of MTA Fillapex in comparison to AH Plus, Pulp Canal Sealer EWT and Sealapex by using stereomicroscope and confocal laser microscopy. 


\section{Material and Methods}

This study was approved by the Human Research Ethics Committee (\# 0402.0.213.000-11).

\section{Inclusion and Exclusion Criteria}

By means of radiographic evaluation, all teeth presenting more than one root canal, incomplete root formation, internal and external resorption, fracture lines, curved roots, or filled/instrumented canals were excluded. Moreover, only the teeth with preserved apical and periapical foramina and measuring $14 \mathrm{~mm}$ from cervical margin to root apex were selected.

\section{Sample Selection}

Forty single-rooted premolars were selected from the tooth bank. By means of radiographic and clinical exams, the teeth were divided into four groups of 10 specimens each and then stored in distilled water and 2.5\% sodium hypochlorite at a 10:1 ratio until standardization of root length, instrumentation and obturation of root canals.

\section{Criteria of Standardization and Root Instrumentation}

All the steps were performed by a single endodontic specialist, who had been previously trained in a pilot study prior to participating in the present research.

The crowns were removed at the cementoenamel junction and the roots were cross-sectioned to standardize the total length at $14 \mathrm{~mm}$. After locating the root canal with an endodontic probe (Odous de Deus, Belo Horizonte, MG, Brazil), the specimens were fixed in a vise (Destak, São Paulo, SP, Brazil) to facilitate the operating procedure.

The canal patency length (CPL) was visually determined by inserting a \#10 K file (Maillefer, Ballaigues, Switzerland) until reaching the apical foramen. Working length (WL) was measured by subtracting $1 \mathrm{~mm}$ from the apical foramen. Canal instrumentation was performed according to the crown-down technique by rotary files (Protaper Universal; Maillefer) until F3 instrument, mounted on electric motor (Silver Reciproc, VDW, Munich, Germany) with 300 rpm and $3 \mathrm{Ncm}$ torque.

Using a gauge 30 needle (Ultradent Products, South Jordan, UT, USA) fitted onto a 3-mL syringe (Ultradent Products), the canals were irrigated with $1 \mathrm{~mL}$ of $5.25 \%$ sodium hypochlorite at every instrument change with a \#10 $K$ file (Maillefer), also used for patency during this interval. After instrumentation, the teeth were irrigated with $2 \mathrm{~mL}$ of 17\% EDTA solution (Fórmula \&t Ação, São Paulo, SP, Brazil) for $3 \mathrm{~min}$ and then activated with a ST-21 ultra-sonic tip fitted onto an Enac device (Osaka, Tokyo, Japan) operating at potency 7 . Next, the canals were irrigated again with 1 $\mathrm{mL}$ solution of $5.25 \%$ sodium hypochlorite and dried with absorbent paper points (Protaper F3; Maillefer).

\section{Obturation of the Root Canal System}

The sample was divided into four groups of ten specimens, which were filled by the following endodontic sealers: G1, AH Plus (Dentsply/Maillefer, Konstanz, Germany); G2, Pulp Canal Sealer EWT (SybronEndo, Orange, CA, USA); G3, Sealapex (SybronEndo, Orange, CA, USA); and G4, MTA Fillapex (Angelus, Londrina, PR, Brazil).

The sealers were manipulated according to the manufacturer's instructions. In order to allow the confocal microscopy analysis to be performed with the tip of the endodontic probe, a small amount of $1 \%$ rhodamine $B$ dye (Sigma-Aldrich, St. Louis, MO, USA) was incorporated into each sealer. The sealers were then inserted into the pulp cavity with a \#30 file used at the working length, painting the canal walls. Next, a F3 gutta-percha cone (Maillefer) was involved in the sealer and introduced into the root canal.

Cone proof and periapical radiographs were performed using Ip-21 film (Kodak Insight, Rio de Janeiro, RJ, Brazil) in order to evaluate its correct filling position within the working length.

Vertical condensation technique using thermoplastic gutta-percha was performed for obturation with an electric heat-carrier device (Touch'n'heat, SybronEndo, Glendora, CA, USA) fitted to the System B stainless steel tip (Touch'n'heat, SybronEndo) for the down-pack phase, where $7 \mathrm{~mm}$ of obturation was removed. Compression was performed by Schilder condensers (Odous de Deus) with sizes ranging from 2 to 4 . The backfill phase was performed by the Obtura IITM device (Obtura Spartan Corp. Fenton, MO, USA), and radiographs were then taken for analysis of the RCS obturation.

Canal entry was cleaned with small cotton balls soaked with isopropyl alcohol. After this procedure, teeth were sealed with a temporary cement barrier (Coltosol; Vigodent, Rio de Janeiro, RJ, Brazil) and then stored in oven at $37^{\circ} \mathrm{C}$ in proper humidity conditions for a 7-day period.

\section{Analysis of the Teeth with Stereo Confocal Laser Scanning Microscopy}

After 7 days, the teeth were sectioned at 2, 4, and 6 $\mathrm{mm}$ from the root apex by a $0.3-\mathrm{mm}$ precision saw (Isomet, Buehler Ltd, llinois, IL, USA) operating at 300 rpm under continuous water refrigeration, similar to Rossetto et al. (12). The dentin segments containing the sealers were placed on glass slides, which were numbered and identified. Next, the slides were submitted to stereo microscopy (Stemi 2000C; Carl Zeiss Jena, Jena, Germany) at 8x magnification for analysis of the obturation quality, whereas photographs of the respective sections were taken with a digital camera (AxioCam MRc5 (Zeiis, Jena, Germany). The specimens were also observed with an inverted confocal laser scanning microscope (TCS-SPE, Leica, Mannheim, Germany). The 
images were processed from a single focal plane at 512 x 512 pixels at 10x/0.30 magnification, and laser diode excitation was achieved at $532 \mathrm{~nm}$. Emission was captured between 545 and $740 \mathrm{~nm}$.

\section{Data Tabulation and Statistical Analysis}

After analysis with stereo confocal laser scanning microscopy, the images were recorded in CD ROM. Image J software (National Institutes of Health, Bethesda, MD, USA) was used for both analysis and data tabulation. For the images generated by the stereo microscope, area values were calculated in $\mathrm{mm}^{2}$ for calculation of total circumference of root canal, the area filled with

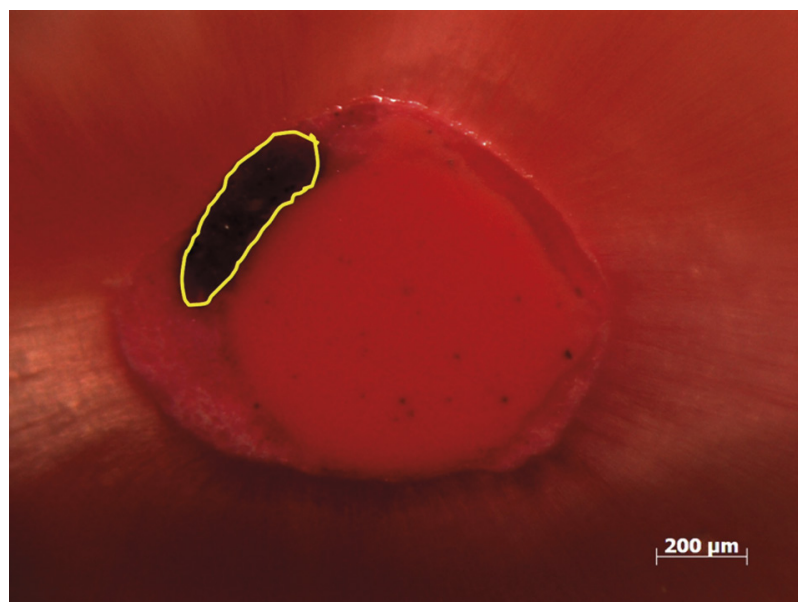

Figure 1. Stereo microscopic image showing failure in the root canal filling - yellow circle.

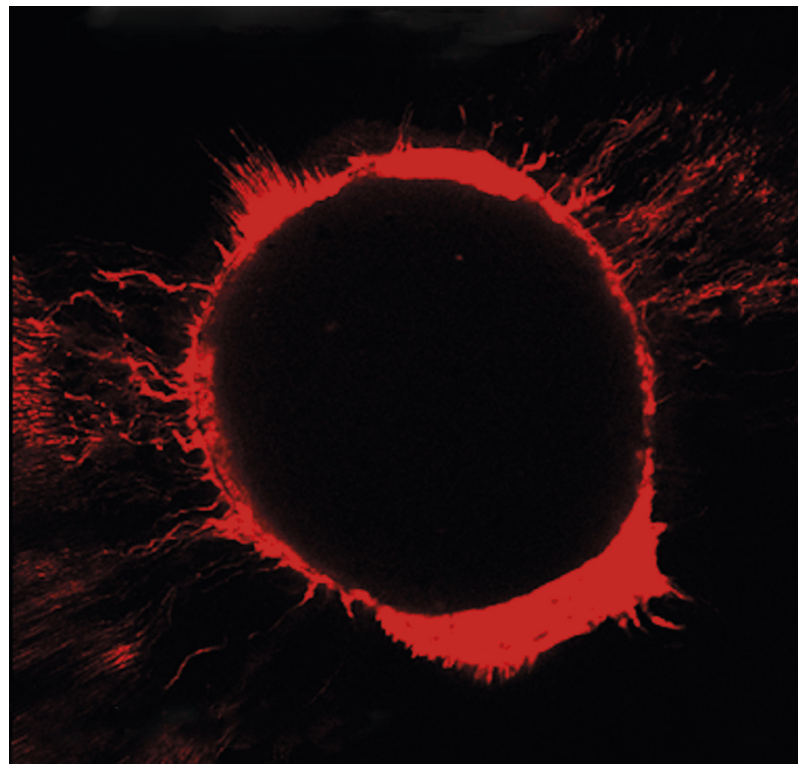

Figure 2. Confocal microscopic image showing the penetration of one of the sealers. gutta-percha and sealer, and areas presenting failures (Fig. 1). Priority was given to comparative measurement of areas filled with sealer and remaining space voids. For visualization of the sealer penetration, images were generated by confocal laser scanning microscopy (Fig. 2). Buccal, lingual, mesial and distal points were established in each image based on the proposed methodologies (1315 ) and linear gauge (in $\mu \mathrm{m}$ ) of each measurement was made by adding and calculating the mean value between them (Fig. 3). After calculating all the measurements, they were recorded on electronic sheets (Excel 2007, Microsoft Corporation, Redmond, WA, USA).

The D'Agostino and Pearson test was employed for assessment of data normality. The variable "percentage of space voids" showed non-normal distribution. As a result, the Friedman's followed by Dunn's multiple comparison tests were performed to assess differences in this variable between regions of each sealer. In addition, the KruskalWallis followed by Dunn's multiple comparison tests were used to assess differences in this variable between sealers in each region.

The variable "sealer penetration" showed normal distribution. Consequently, the repeated measures two-way ANOVA followed by post-hoc Bonferroni test was used to assess differences in this variable between regions of each sealer. In addition, two-way ANOVA followed by Bonferroni post-hoc analysis was employed to assess differences in this variable between sealers in each region.

All tests were performed by GraphPad software (GraphPad Software, San Diego, CA, USA) at a significance level of $5 \%$.

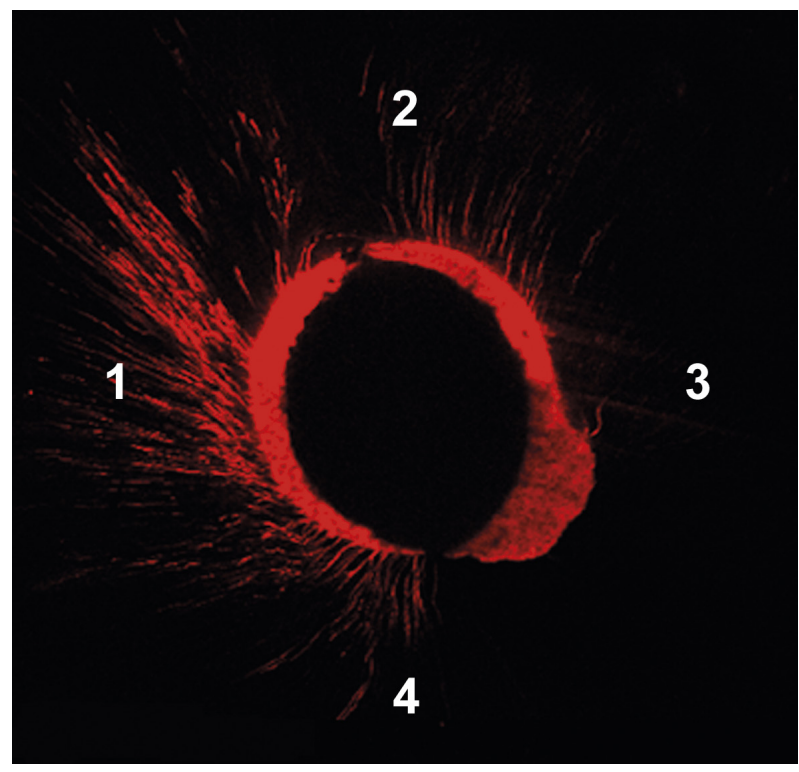

Figure 3. Confocal microscopic image with the four points standardized for linear gauge. $1=$ mesial; $2=$ buccal; $3=$ distal; $4=$ palatal. 


\section{Results}

The results are presented in Tables 1 and 2 . From the four endodontic sealers, 40 sections were assessed at 2, 4 and 6 $\mathrm{mm}$ from the root apex, thus totalizing 120 sections in order to evaluate: the void spaces in the filling material (Table 1) and the dentinal penetration of the sealers (Table 2).

Regarding assessment of void spaces in the filling material, no statistically significant difference was found among the four endodontic sealers evaluated at $2 \mathrm{~mm}$ from the root apex (Kruskal-Wallis test and Dunn's multiple comparison test, $p>0.05$; Table 1 ). Statistically significant difference was observed between MTA Fillapex and Pulp Canal Sealer EWT as well as between MTA Fillapex and AH Plus at $4 \mathrm{~mm}$ from the root apex (Kruskal-Wallis and Dunn's multiple comparison tests, $\mathrm{p}<0.05$; Table 1). At 6 $\mathrm{mm}$ from the root apex, statistically significant difference was observed between MTA Fillapex and Pulp Canal Sealer EWT as well as between MTA Fillapex and Sealapex (KruskalWallis and Dunn's multiple comparison tests, $p<0.05$; Table 1). When the distances from the root apex were compared

\begin{tabular}{|c|c|c|c|}
\hline $\begin{array}{l}\text { Endodontic } \\
\text { sealers }\end{array}$ & $2 \mathrm{~mm}$ & $4 \mathrm{~mm}$ & $6 \mathrm{~mm}$ \\
\hline $\mathrm{AH}$ Plus & $0(0-2.33)^{\mathrm{A}, \mathrm{a}}$ & $0(0-4.11)$ A,a & $0(0-6.62)$ A,B,a \\
\hline $\begin{array}{l}\text { Pulp Canal } \\
\text { Sealer EWT }\end{array}$ & $0(0-0)$ A,a & $0(0-3.33)$ A,a & $0(0-14.52)^{A, a}$ \\
\hline Sealapex & $0(0-3.85)^{A, a}$ & $0(0-2.26)^{A, B, a}$ & $0(0-0.18)^{A, a}$ \\
\hline MTA Fillapex & $0(0-0) A, a$ & $8.76(0-69.23)$ B,a,b & $10.03(0-53.33)^{B, b}$ \\
\hline
\end{tabular}

A,B Within columns, medians followed by the same uppercase letter are not significantly different from each other ( $p>0.05)$. $P$ values obtained by using Kruskal-Wallis test followed by Dunn's multiple comparison test. a,b Within rows, medians followed by the same lowercase letter are not significantly different from each other ( $p>0.05$ ). $P$ values were obtained by using Friedman's test followed by Dunn's multiple comparison test.

Table 2. Mean and standard deviation values for "penetration of endodontic sealer" (in $\mu \mathrm{m}$ )

\begin{tabular}{lccc}
\hline $\begin{array}{l}\text { Endodontic } \\
\text { sealers }\end{array}$ & $2 \mathrm{~mm}$ & $4 \mathrm{~mm}$ & $6 \mathrm{~mm}$ \\
\hline AH Plus & $83.07 \pm 50.79^{\mathrm{A}, \mathrm{a}}$ & $139.9 \pm 70.19^{\mathrm{A}, \mathrm{B}, \mathrm{b}}$ & $196.4 \pm 79.54^{\mathrm{A}, \mathrm{c}}$ \\
Pulp Canal & $47.79 \pm 60.85^{\mathrm{A}, \mathrm{a}}$ & $89.04 \pm 66.71^{\mathrm{A}, \mathrm{a}, \mathrm{b}}$ & $103.3 \pm 48.99^{\mathrm{B}, \mathrm{b}}$ \\
Sealer EWT & $105.1 \pm 63.24^{\mathrm{A}, \mathrm{a}}$ & $139.8 \pm 75.32^{\mathrm{A}, \mathrm{B}, \mathrm{a}}$ & $153.4 \pm 67.59^{\mathrm{A}, \mathrm{B}, \mathrm{a}}$ \\
Sealapex & $157.0 \pm 50.87^{\mathrm{B}, \mathrm{b}}$ & $163.6 \pm 40.64^{\mathrm{A}, \mathrm{B}, \mathrm{b}}$ \\
\hline
\end{tabular}

A,B Within columns, means followed by the same uppercase letter are not significantly different from each other ( $p>0.05)$. $P$ values were obtained by using two-way ANOVA followed by post-hoc Bonferroni's test. a,b,c Within rows, means followed by the same lowercase letter are not significantly different from each other $(p>0,05)$. $P$ values were obtained by using repeated measurements two-way ANOVA followed by post-hoc Bonferroni's test. in each sealer, only MTA Fillapex showed statistically significant difference between 2 and $6 \mathrm{~mm}$ from the root apex (Friedman's and Dunn's multiple comparison tests, $\mathrm{p}<0.05$; Table 1).

Concerning dentinal penetration of the sealers, there was no statistically significant difference between the sealers at $2 \mathrm{~mm}$ from the root apex (two-way ANOVA and post-hoc Bonferroni's test, $p>0.05$; Table 2). However, at 4 $\mathrm{mm}$ from the root apex, there were statistical differences between Pulp Canal Sealer EWT and MTA Fillapex (two-way ANOVA and post-hoc Bonferroni's test, $p<0.05$; Table 2). At $6 \mathrm{~mm}$ from the root apex, there were also differences between Pulp Canal Sealer EWT and AH Plus (two-way ANOVA and post-hoc Bonferroni's test, $p<0.05$; Table 2). When the distances from the root apex were compared in each sealer, AH Plus and MTA Fillapex showed statistically significant difference between 2 and $4 \mathrm{~mm}$ from the root apex, AH Plus, Pulp Canal Sealer EWT and MTA Fillapex displayed statistically significant difference between 2 and $6 \mathrm{~mm}$ from the root apex, and AH Plus showed statistically significant difference between 4 and $6 \mathrm{~mm}$ from the root apex (repeated-measures two-way ANOVA and post-hoc Bonferroni's test, $\mathrm{p}<0.05$; Table 2).

\section{Discussion}

Flow and adhesiveness are essential properties in the choice of the endodontic sealer, since they provide sealing to the root canal system. Flow allows adequate setting time and penetration of the sealer into the dentinal tubules. Penetration of the sealer into dentinal tubules may favor contact and confinement of microorganisms in the dentinal tubules, providing better antiseptic action. Whereas adequate flow ability allows filling the irregularities, isthmuses and accessory canals, high flow may result in apical extrusion, leading to injury of the periapical tissues because of the cytotoxicity of the sealers $(5,16)$. Adhesiveness allows the material to remain on the walls, thus aiding the stability of filling mass. In view of this, endodontic sealers are still inadequate (17).

Stereomicroscope is pointed out as an important tool to assess the filling quality, since it is safe and shows details of the adaptation of guttapercha and sealer, including areas inadequately filled during root canal filling therapy (18).

Confocal laser scanning microscopy was used in the present study to analyze the flow of endodontic sealers because it is a technology using a combination of optical microscopy, physicalchemical principles and computing resources for acquisition and processing of images $(14,18,19)$. The system uses a laser source to promote 
excitation of fluorophores. The laser beams may diffuse through the dentin, enamel and biofilms, thus detecting their inner structures and forming several two-dimensional images (20).

Confocal laser scanning microscopy has some advantages compared to scanning electron microscopy, including histological evaluation and other methodologies for assessing the adaptation of endodontic sealers (18-20). This technology may also be used in microbiological studies for quantifying bacteria within dentinal tubules (8).

The aim is to have minimum sealer thickness and most of the root canal circumference filled with gutta-percha, thus favoring adaptation of filling material and a deeper penetration of the endodontic sealer into dentinal tubules and ramifications of the root canal system $(17,21)$. The sealers have different physicochemical properties, due their composition, which may be related to the difference in some of their behaviors.

Pulp Canal Sealer was found to be statistically inferior to MTA Fillapex at $4 \mathrm{~mm}$ from the root apex and AH Plus at $6 \mathrm{~mm}$ from the root apex regarding depth and penetration into dentinal tubules. It suggests that this finding is due to the presence of silver crystals in the chemical composition of the sealer, which on one hand allows excellent radiopacity but on the other hand can obliterate the opening of dentinal tubules, thus hampering sealer penetration. On the other hand, AH Plus and MTA Fillapex present high flowability, facilitating intratubular penetration $(22,23)$

Although endodontic sealers have shown similar results in some analyses, they did not penetrate the whole extension of the dentinal tubules. The deepest penetration of the sealer in all experimental groups was observed at 6 , 4 and $2 \mathrm{~mm}$ from the root apex, in this order, which agrees with other studies $(9,15,24)$. These facts may be due to the greater diameter of the dentinal tubules or lesser density of the dentin (25).

Regarding the presence of space voids in the filling material, MTA Fillapex was found to be statistically inferior compared to Pulp Canal Sealer and AH Plus at $4 \mathrm{~mm}$ from the root apex and to Pulp Canal Sealer and to Sealapex at $6 \mathrm{~mm}$ from the root apex. This behavior is probably because of the high solubility (22) and no presence of hydrophilic characteristics (26). However, with regards to physicalchemical properties, this sealer presented satisfactory results compared to other sealers $(7,27)$.

Complete filling of the root canal system requires the use of materials and techniques that be able to provide a fluid tight seal to entire canal to prevent bacterial microleakage $(3,5,17)$. Therefore, it is very important to carry out further studies aimed at investigating other important properties and characteristics, always seeking to develop an ideal endodontic sealer.
Based on the findings obtained in the present study it may be concluded that: 1 . The endodontic sealers were found to have a good and similar performance regarding filling material adaptation the root canal walls, except for MTA Fillapex, which showed more failures at 4 and 6 $\mathrm{mm}$ from the root apex; 2 . The sealers also had a similar behavior regarding their ability to penetrate deeply into the dentinal tubules, except for the Pulp Canal Sealer EWT, which had a shorter penetration than MTA Fillapex and AH Plus at 4 and $6 \mathrm{~mm}$ from the root apex, respectively; 3. No sealer was able to penetrate the whole extension of the dentinal tubules.

\section{Resumo}

O objetivo deste estudo foi avaliar a efetividade da obturação e capacidade de penetração no interior dos túbulos dentinários dos cimentos: AH Plus, Pulp Canal Sealer EWT, Sealapex e MTA Fillapex, associado à técnica de obturação da condensação vertical da guta-percha termoplastificada. Selecionou-se 40 dentes unirradiculados. Após o preparo químicomecânico e obturação, secções das raízes (a 2, 4 e 6 mm do ápice) foram obtidas e analisadas através de microscopia estéreo e confocal de varredura a laser. Os dados foram tabulados e analisados estatisticamente. Em relação à avaliação de espaços vazios na obturação a $2 \mathrm{~mm}$, os cimentos apresentaram resultados similares, entretanto a 4 e $6 \mathrm{~mm}$ MTA Fillapex apresentou desempenho inferior em relação a $\mathrm{AH}$ Plus (a $4 \mathrm{~mm}$ ), Pulp Canal Sealer EWT (a 4 e 6 mm) e Sealapex $($ a 6 mm) $(p<0,05)$. Em relação à capacidade de penetração nos túbulos dentinários a $2 \mathrm{~mm}$, os cimentos apresentaram resultados similares, contudo a 4 e $6 \mathrm{~mm}$, o Pulp Canal Sealer EWT mostrou-se inferior ao MTA Fillapex e AH Plus, respectivamente $(p<0,05)$. Os quatro cimentos foram similares em relação à adaptação da obturação nas paredes dos canais radiculares, exceto o MTA Fillapex, que evidenciou falhas a 4 e $6 \mathrm{~mm}$. Na capacidade de penetração nos túbulos dentinários, os cimentos foram equivalentes, exceto o Pulp Canal Sealer EW que se mostrou inferior a 4 e $6 \mathrm{~mm}$, quando comparado com MTA Fillapex e $\mathrm{AH}$ Plus, respectivamente.

\section{Acknowledgements}

The authors are grateful to Fundação de Amparo à Pesquisa do Estado de Minas Gerais (FAPEMIG).

\section{References}

1. Nair PN. Pathogenesis of apical periodontitis and the causes of endodontic failures. Crit Rev Oral Biol Med 2004;15:348-381.

2. Siqueira Jr. JF, Rôças IN. Clinical implications and microbiology of bacterial persistence after treatment procedures. J Endod 2008;34:1291-301.

3. Venturi, M. Evaluation of canal filling after using two warm vertical gutta-percha compaction techniques in vivo: a preliminary study. Int Endod J 2006;39:538-546.

4. Kokkas AB, Boutsioukis A, Vassiliadis LP, Stavrianos CK. The influence of the smear layer on dentinal tubule penetration depth by three different root canal sealers: an in vitro study. J Endod 2004;30:100-102.

5. Orstavik, D. Materials used for root canal obturation: technical, biological and clinical testing. Endod Top 2005;12:25-38.

6. Wang Z, Shen Y, Haapasalo M. Effectiveness of endodontic disinfecting solutions against young and old Enterococcus faecalis biofilms in dentin canals. J Endod 2012;38:1376-1379.

7. Vitti RP, Pratib C, Silva EJN, Sinhoreti MAC, Zanchic $\mathrm{CH}$, SousaSilva MG, et al.. Physical properties of MTA Fillapex sealer. J Endod 2013;39:915-918.

8. Ma J, Wang Z, Shen Y, Haapasalo M. A new noninvasive model to study the effectiveness of dentin disinfection by using confocal laser 
scanning microscopy. J Endod 2011;37:1380-1385.

9. Chandra SS, Shankar P, Indira R. Depth of penetration of four resin sealers into radicular dentinal tubules: a confocal microscopic study. J Endod 2012;38:1412-1416.

10. Duarte MA, Demarchi ACCO, Yamashita JC, Kuga MC, Fraga SC. pH and calcium ion release of 2 root-end filling materials. Oral Surg Oral Med Oral Pathol Oral Radiol and Endod 2003;95:345-347.

11. Silva EJNL, Rosa TP, Herrera DR, Jacinto RC, Gomes BPFA, Zaia AA. Evaluation of cytotoxicity and physicochemical properties of calcium silicate-based endodontic sealer MTA Fillapex. J Endod 2013;39:274277.

12. Rossetto DB, Fernandes SL, Cavanego BC, Duarte MAH, Ordinola-Zapata $\mathrm{R}$, Andrade $\mathrm{FB}$. Influence of the method in root canal using active lateral compaction techniques. Braz Dent J 2014;25:295-301.

13. Bitter K, Paris S, Martus P, Schartner R, Kielbassa AM. A confocal laser scanning microscope investigation of different dental adhesives bonded to root canal dentine. Int Endod J 2004;37:840-848.

14. Gharib SR, Tordik PA, Imamura GM, Baginski TA, Goodell GG. A confocal laser scanning microscope investigation of the Epiphany obturation system. J Endod 2007;33:957-961.

15. Ordinola-Zapata R, Bramante CM, Graeff MS, del Carpio Perochena A, Vivan RR, Camargo EJ, et al.. Depth and percentage of penetration of endodontic sealers into dentinal tubules after root canal obturation using a lateral compaction technique: a confocal laser scanning microscopy study. Oral Surg Oral Med Oral Pathol Oral Radiol Endod 2009;108:450-457.

16. Duarte MA, Ordinola-Zapata $R$, Bernardes RA, Bramante CM, Bernardinelli N, Garcia RB, et al.. Influence of calcium hydroxide association on the physical properties of $\mathrm{AH}$ Plus. J Endod 2010;36:1048-1051.

17. De-Deus G, Coutinho-Filho T, Reis C, Murad C, Paciornik S. Polymicrobial leakage of four root canal sealers at two different thicknesses. J Endod 2006;32:998-1001.

18. Chauhan R, Tikku A, Chandra A. Detection of residual obturation material after root canal retreatment with three different techniques using a dental operating microscope and a stereomicroscope: An in vitro comparative evaluation. J Conserv Dent 2012;15:218-222.

19. Patel DV, Sherriff M, Ford TR, Watson TF, Mannocci F. The penetration of RealSeal primer and Tubliseal into root canal dentinal tubules: a confocal microscopic study. Int Endod J 2007;40:67-71.

20. Kagayama M, Sasano Y, Sato H, Kamakura S, Motegi K, Mizogushi I. Confocal microscopy of dentinal tubules in human tooth stained with alizarin red. Anat Embryol 1998;199:233-238.

21. Wu MK, Wesselink PR, Boersma J. A 1-year follow-up study on leakage of four root canal sealers at different thicknesses. Int Endod J 1995;28:185-189.

22. Amoroso-Silva PA, Guimarães BM, Marciano MA, Duarte MA, Cavanego $B C$, Ordinola-Zapata $\mathrm{R}$, et al.. Microscopic analysis of the quality of obturation and physical properties of MTA Fillapex. Microsc Res Tech Microsc Res Tech 2014;77:1031-1036.

23. Vilanova WV, Carvalho-Junior JR, Alfredo E, Sousa-Neto MD, SilvaSousa YT. Effect of intracanal irrigants on the bond strength of epoxy resin based and methacrylate resin-based sealers to root canal walls. Int Endod J 2001;45:42-48.

24. Weis MV, Parashos $\mathrm{P}$, Messer HH. Effect of obturation technique on sealer cement thickness and dentinal tubule penetration. Int Endod J 2004;37:653-663.

25. Mjör IA, Smith MR, Ferrari M, Mannocci $F$. The structure of dentine in the apical region of human teeth. Int Endod J 2001;34:346-353.

26. Nagas E, Uyanik MO, Eymirli A, Cehreli ZC, Vallittu PK, Lassila LV, et al.. Dentin moisture conditions affect the adhesion of root canal sealers. J Endod 2012; 38:240-244.

27. Vitti RP, Pratib C, Silva EJN, Sinhoreti MAC, Zanchic CH, Sousa-Silva $M G$, et al.. Chemical-physical properties of experimental root canal sealers based on butyl ethylene glycoldisalicylate and MTA. Dent Mater 2013;29:1287-1294. 